Article

\title{
InSAR-Based Mapping of Tidal Inundation Extent and Amplitude in Louisiana Coastal Wetlands
}

\author{
Talib Oliver-Cabrera * and Shimon Wdowinski
}

Division of Marine Geosciences, University of Miami, Miami, FL 33149, USA; swdowinski@rsmas.miami.edu

* Correspondence: toliver@rsmas.miami.edu; Tel.: +1-305-421-4928

Academic Editors: Javier Bustamante, Alfredo R. Huete and Prasad S. Thenkabail

Received: 29 February 2016; Accepted: 3 May 2016; Published: 7 May 2016

\begin{abstract}
The Louisiana coast is among the most productive coastal areas in the US and home to the largest coastal wetland area in the nation. However, Louisiana coastal wetlands have been disappearing at an alarming rate due to natural and anthropogenic processes, including sea level rise, land subsidence and infrastructure development. Wetland loss occurs mainly along the tidal zone, which varies in width and morphology along the Louisiana shoreline. In this study, we use Interferometric Synthetic Aperture Radar (InSAR) observations to detect the extent of the tidal inundation zone and evaluate the interaction between tidal currents and coastal wetlands. Our data consist of ALOS and Radarsat-1 observations acquired between 2006-2011 and 2003-2008, respectively. Interferometric processing of the data provides detailed maps of water level changes in the tidal zone, which are validated using sea level data from a tide gauge station. Our results indicate vertical tidal changes up to $30 \mathrm{~cm}$ and horizontal tidal flow limited to $5-15 \mathrm{~km}$ from open waters. The results also show that the tidal inundation is disrupted by various man-made structures, such as canals and roads, which change the natural tidal flow interaction with the coast.
\end{abstract}

Keywords: InSAR; wetlands; tidal inundation; remote sensing

\section{Introduction}

Louisiana has more coastal wetlands than any other state in the US, covering an area of roughly $20,000 \mathrm{~km}^{2}$. These coastal wetlands provide important ecosystem services including habitat for a wide variety of wildlife, storm protection, flood control, water storage and others. Louisiana coastal wetlands also have high economical values, including habitat for fishing industry, recreational activities and location for oil and gas exploitation. The excessive use of the ecosystem services, climatic drivers, and human sprawl have threaten these valuable wetlands [1]. Coastal Louisiana has undergone a decrease in land area of approximately $4747 \mathrm{~km}^{2}$ in the period between 1932 and 2010, reaching a rate of $42.9 \mathrm{~km}^{2}$ of yearly wetland loss between 1985 to 2010 [2]. To protect these prolific resources, it is important to monitor and quantify the circumstances that provoke wetland loss in coastal Louisiana.

Monitoring coastal wetlands is a difficult task due to their large extent and hostile environment, which limit ground-based efforts. Remote sensing observations provide a suitable solution for analyzing large areas in a safe and economic manner. Several remote sensing studies were conducted to analyze and monitor Louisiana's coastal wetlands. Penland et al. [3] used aerial photography to describe land loss of the Mississippi River delta plain and explained the loss by three main processes: erosion, submergence and direct removal. Steyer et al. [4] monitored vegetation changes by generating vegetation indices from MODIS and Landsat imagery, using Normalized Difference Vegetation Index (NDVI) to quantify the impacts of hurricanes Katrina and Rita (2005) on the coastal marshes of Louisiana. Barras et al. [5] used aerial photography and Landsat images to estimate land loss of coastal Louisiana; they also projected the land loss to 2050. Ramsey et al. [6] analyzed L-band and C-band Synthetic Aperture Radar (SAR) amplitude combined with Landsat imagery to study flooding in 
coastal marshes of Louisiana. They created marsh inundation maps by comparing SAR backscatter from marshes during flooding and non-flooding conditions. A detailed description of the use of the different remote sensing techniques for wetland observations was recently summarized by Gallant [1]. The above studies provide a good assessment of vegetation or land changes. However, they have limited capability to detect water level changes in tidal zone, where active land loss occurs. Coastal wetlands and water levels are interrelated, as water level changes may induce shifts that produce disturbances or environmental changes [7].

A different remote sensing method that can detect water level changes in wetlands is Interferometric Synthetic Aperture Radar (InSAR). Studies have shown that InSAR observations can detect water level change with 3-5 cm accuracy level over wide wetland areas (e.g., [8-11]). InSAR measures phase difference between two SAR acquisitions from roughly the same location in space. The result generated from the phase-difference operation is a phase change map, called an interferogram, which is sensitive to changes of the Earth's surface [12]. Interferograms are widely used to measure surface displacements after an earthquake, urban subsidence due to ground water withdrawal, magmatic-induce deformation and, as in the case of this research, water-level changes in wetlands.

Most wetland InSAR studies were applied to inland freshwater wetlands, where hydrological changes occur within days or weeks. Several studies showed that the technique works well in woody wetlands $[11,13]$. Only few studies applied the technique to study water level changes in coastal areas. Ramsey et al. [14] analyzed four tandem ERS-1/2 interferograms and noticed phase changes between freshwater and saltwater vegetation. Wdowinski et al. [8] also noticed phase change occurring along the transition between fresh and salt-water vegetation in the western Everglades (Florida). Recently, Wdowinski et al. [15] observed tide inundation in the coastal wetlands of the Florida Everglades, showing the feasibility of InSAR for detecting tidal inundation propagation and mapping the tidal zone.

In this study we use Synthetic Aperture Radar (SAR) data acquired by the ALOS and Radarsat-1 satellites as well as tide gauge data to map the tidal inundation extent and water level changes throughout the coastal wetlands of Louisiana. We were able to detect water level changes up to $30 \mathrm{~cm}$ in some areas. Our observations also show disruptions of water inlet into the wetlands due to man-made structures.

\section{Louisiana Coastal Wetlands}

Louisiana's coastal wetlands are located in the southern part of the state, along the entire state shoreline. Sedimentation processes induced by the Mississippi river dominate the morphology of the coast. The shift of the river's deposition plume formed two main features, the Chenier Plain and the Mississippi Deltaic Plain [16] (Figure 1). The Chenier Plain is located along the western part of the state, where the coastline's morphology consists of wooded beach ridges termed Cheniers and mudflats covered by swamps and marshes [17]. The Mississippi Deltaic Plain is located along the eastern shoreline, where the coastal morphology is a product of sediment deposition. It is also the present location of the Mississippi river delta.

Wetland vegetation varies along the coast depending mostly on water conditions due to mixed inputs of fresh and salt-water within the coastal zone. Two main types of wetland vegetation are found along the Louisiana coast, forested wetlands, termed swamps, and herbaceous wetlands, termed marshes [18]. Swamps are mostly found in freshwater zones whereas most marshes are located in brackish or saline water.

The map in Figure 1 shows a vegetation transition along Louisiana's coast. The vegetation type works roughly as a marker of the extents of salt-water inputs, for example, the presence of fresh-water marshes in areas that are not affected by ocean tide. The areas on the map with color green represent vegetation that is better adapted to the salt-water intrusions. Meanwhile the purple and orange represent vegetation that requires fresh-water inputs to live. The transition zone between fresh and 
salt water is marked by the presence of brackish marsh (aqua green color) and intermediate marsh (purple color).

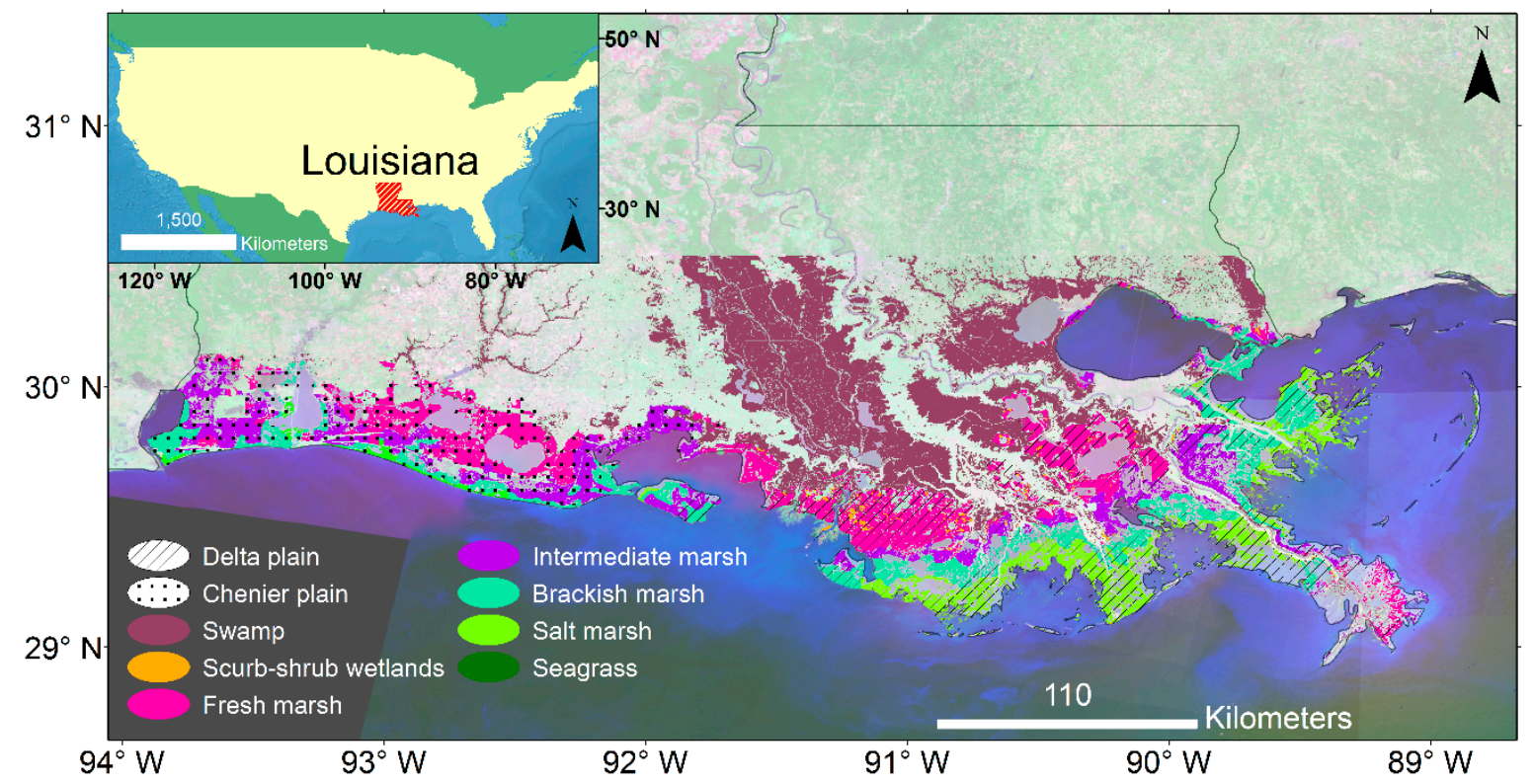

Figure 1. Location map and wetland classification generated using Gulf-Wide Information System (G-WIS) [19], Landsat mosaic [20] as background and Natural Earth data used for the location map. The wetlands with dot pattern correspond to the Chenier Plain and the hatch pattern to the Mississippi River Delta plain.

Louisiana coastal wetlands have been threatened by both natural (e.g., sea level rise) and anthropogenic (e.g., infrastructure development) processes causing an average loss of $43 \mathrm{~km}^{2}$ of wetlands per year [2]. Boesch et al. [16] define the loss of wetlands as the change from vegetated wetlands to uplands or drained areas and to nonvegetated wetlands or submerged habitats. Between 1956 and 2004 the state lost around $3000 \mathrm{~km}^{2}$ of wetlands that were transformed to open water [21]. According to Penland et al. [3] between 1932 and 1990, 26\% of the coastal land loss was due to natural erosion processes, $36 \%$ due to oil and gas extraction, and $23 \%$ was due to altered hydrology product of multiple activities as channel construction for navigation or levees. Furthermore the construction of flood control levees has interrupted the normal sediment deposition from the Mississippi River, which created a deficit of deposited material, and resulted in land loss [22]. The vegetation in the submerged areas dies or has a limited growth due to hypoxia, transforming the vegetated areas into tidal mudflats [23].

\section{Data and Data Processing}

This study is based on data acquired by two SAR satellites, Advanced Land Observing Satellite (ALOS) and Radarsat-1 (Table S1). ALOS was launched by the Japanese Space Agency (JAXA) and operated from 2006 to 2011. It was equipped with L-band (23.62 cm wavelength) radar and had a repeated orbit of 46 days. Radarsat- 1 was launched by the Canadian Space Agency in 1995 . It was equipped with C-band (5.66 cm wavelength) radar and had a repeat orbit resolution of 24 days (Table 1). We used all available data acquired by both satellites over the entire length of coastal Louisiana (Figure 2) that are archived in the User Remote Sensing Access (URSA) at the Alaska Satellite Facility (ASF) data pool [24]. We used a total of 246 ALOS scenes and 154 Radarsat-1 scenes (Table 1). 
Table 1. Scenes available and satellite information.

\begin{tabular}{cccccc}
\hline Satellite & Path & Frames & Orbit & Number of Scenes & Date \\
\hline ALOS & 164 & 570 and 580 & Ascending & 36 & $2006-2011$ \\
ALOS & 165 & 570 and 580 & Ascending & 40 & $2007-2011$ \\
ALOS & 166 & 570 and 580 & Ascending & 40 & $2007-2010$ \\
ALOS & 167 & 570 and 580 & Ascending & 38 & $2007-2011$ \\
ALOS & 168 & 570 and 580 & Ascending & 50 & $2007-2011$ \\
ALOS & 169 & 580 & Ascending & 18 & $2006-2011$ \\
ALOS & 170 & 580 & Ascending & 24 & $2006-2011$ \\
Radarsat-1 & 94 & 74 and 75 & Ascending & 72 & $2002-2007$ \\
Radarsat-1 & 337 & 74 and 75 & Ascending & 82 & $2002-2008$ \\
\hline
\end{tabular}

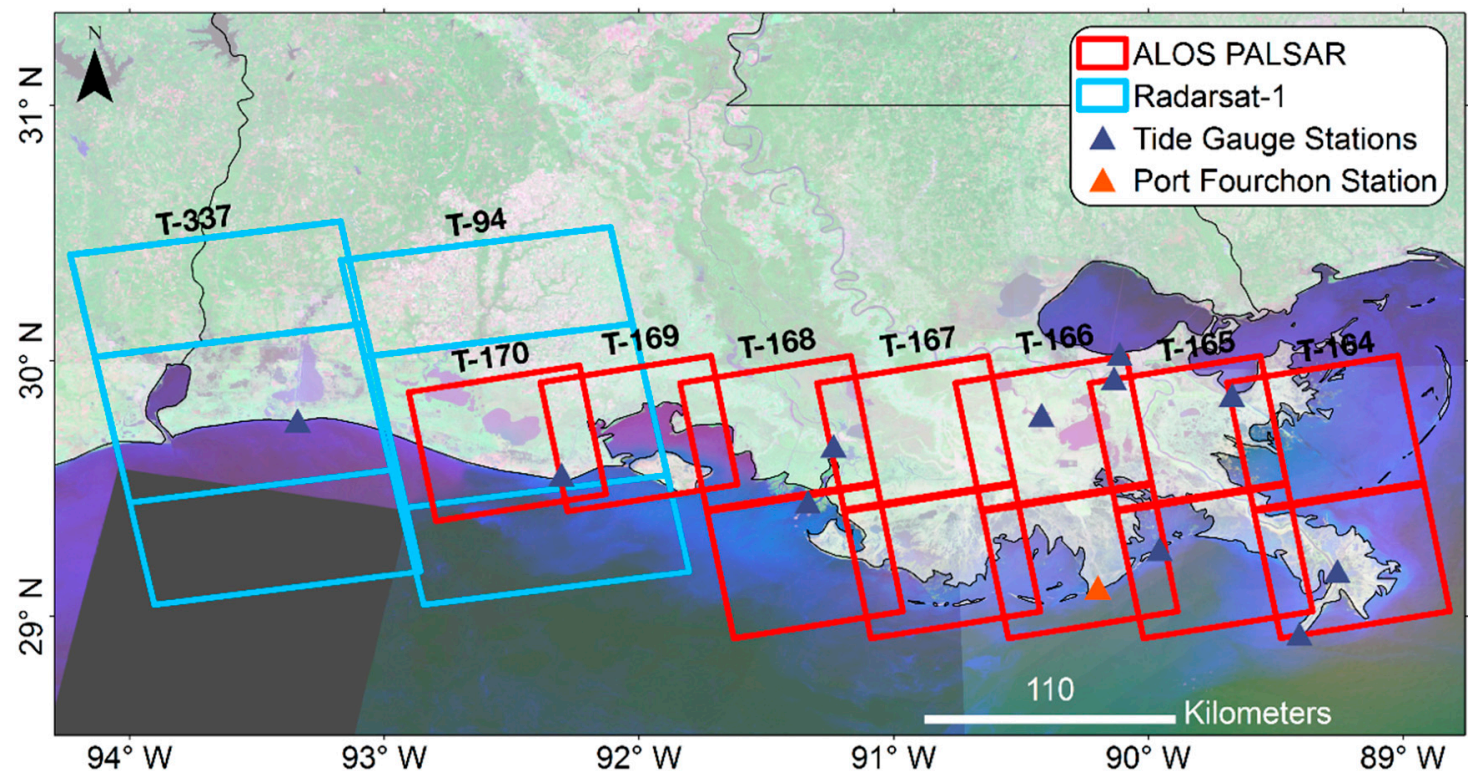

Figure 2. Location map of the Synthetic Aperture Radar (SAR) scenes and the available National Oceanic and Atmospheric Administration (NOAA) tide gauge stations for Louisiana (triangles). The orange triangle marks the location of the tide gauge used in this study.

InSAR data processing aims at detecting phase difference between two acquisitions to generate interferograms, reflecting surface changes between the two acquisitions. InSAR is regularly used to measure displacements of solid surfaces. However, in the case of wetlands, coherent interferometric signal occurs due to double bounce scattering, from the water surface and vegetation, to measure water level changes [25,26]. Data was processed using the ROI_PAC package [27], with 4-8 looks in order to co-register pairs of images. Co-registration searches similarities in morphology between two acquisitions and the looks are an average of pixels with the similar coherence. A lower threshold of looks provides higher resolution results. However, due to the lack of topography in the area, the use of a lower threshold of looks does not permit proper co-registering of the SAR images. Unlike most InSAR applications, we evaluated both filtered and unfiltered results and we didn't unwrap the interferograms. As wetland InSAR phase changes tend to be localized, we avoided these commonly used processing steps, which can affect localized signal in order to increase signal to noise ratio.

Fringes represent phase changed due to water level changes in the interferograms, in which each fringe corresponds to a distance change of $\lambda / 2$, where $\lambda$ is the wavelength of the SAR sensor. Because phase changes in wetlands predominantly reflect vertical movement of the surface, the line of sight (LOS) measurement can be translated to vertical movement, by accounting for the acquisition geometry. The translation from LOS to vertical movement is inversely proportional to the cosine of the acquisition's incidence angle [28]. Based on interferogram interpretation, a vector line representing the 
tidal inundation extents along the coast of Louisiana was digitized. The InSAR detected extents follow the observed phase changes and disruptions along the coast.

Previous studies indicate that the coherence of wetland interferograms is very sensitive to the temporal and perpendicular baselines (e.g., [11,13]). However, the temporal baseline contribution varies depending on the sensor and wetland types. Kim et al. [11] showed that fresh water wetlands with woody vegetation keep better coherence than herbaceous wetlands, mainly because tree trunks tend to be stable scatterers over time, whereas soft-stemmed vegetation are altered by vegetation growth and wind. In order to obtain high coherence interferograms, we generate interferograms with short temporal baselines, 46-92 days for ALOS data and 24-48 days for Radarsat- 1 data.

In addition to the satellite data, we also used tide gauge records from Port Fourchon station (Figure 2) installed and operated by the National Oceanic and Atmospheric Administration (NOAA). The tide gauge data is sampled every $6 \mathrm{~min}$ and is available online [29].

\section{Results}

We analyzed a total of seven ALOS and two Radarsat-1 tracks and generated an average of 10 interferograms per track with temporal baseline ranging between 24-48 days for Radarsat-1 and 46-92 for ALOS. We present here eight representative interferograms, some were combined into a mosaic map that covers the extent of Louisiana's coastline (Figure 3). The rest of the interferograms are presented in the supplementary materials (Figure S1). The mosaic map shows fringe patterns over both inland and coastal areas. The inland fringe patterns are mostly a result of water level changes in wetlands or agriculture activities, like the ones on the central area of tracks 168 and 167. Long wavelength fringes $(20-40 \mathrm{~km})$ in the north part of the interferogram from track 165 and 168 are most likely phase changes due to atmospheric effects [10]. Fringe discontinuities occur along swath edges, because the selected interferograms are from different time periods and, hence, represent distinct signal response according to phase changes of each interferogram. We processed ALOS data of the entire coastline. However, the produced interferograms were unable to detect details from the Chenier plain coast. Thus we present Radarsat-1, which has a shorter wavelength interferograms, over the Chenier plain and ALOS interferograms over the Mississippi River delta.

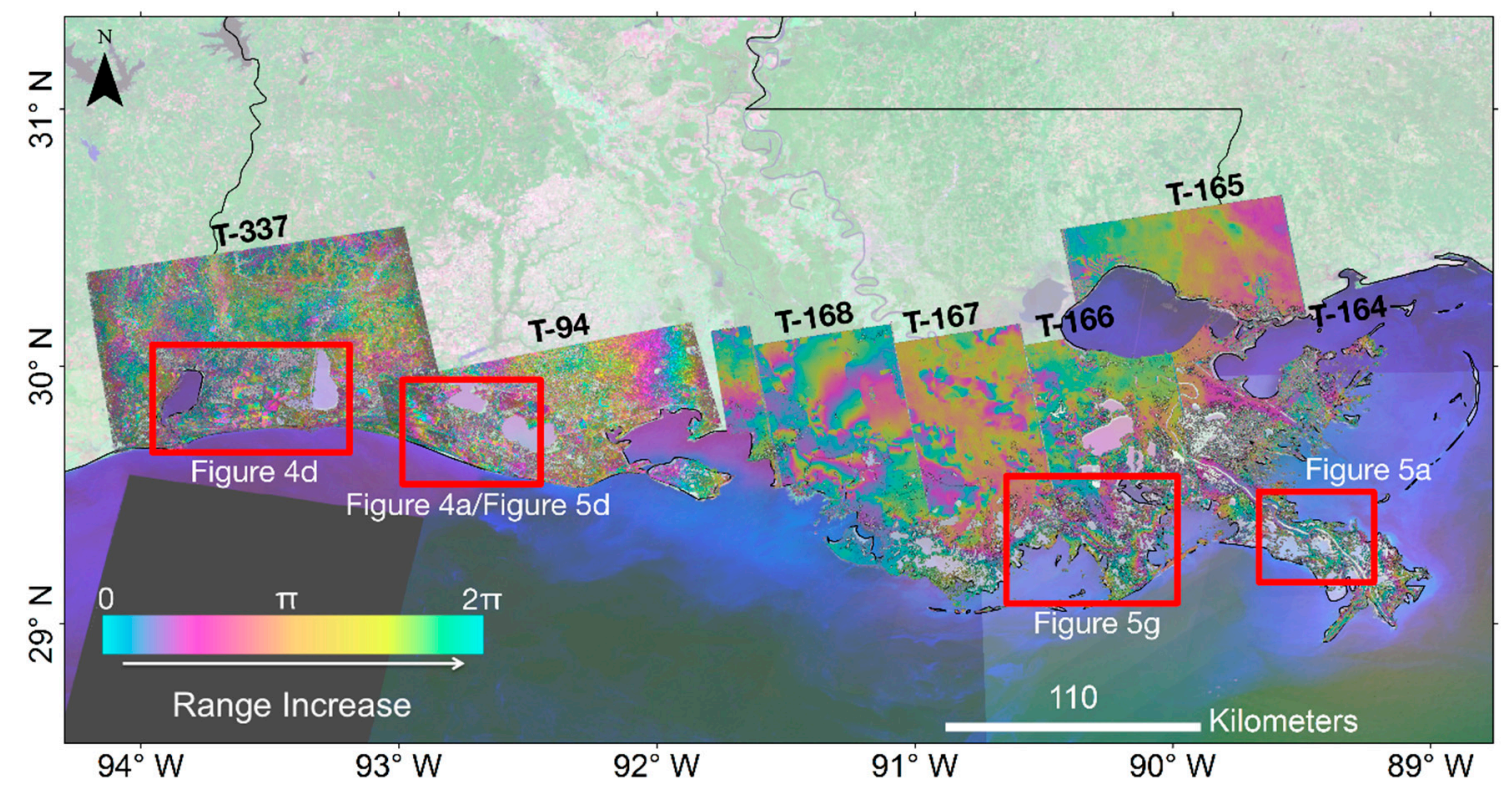

Figure 3. Mosaic of Radarsat-1 (left side) and ALOS (right side) interferograms for coastal Louisiana. The red frames show the location of enlarged interferograms presented in Figures 4 and 5. 
The L-band ALOS interferograms show better coherence than those obtained using C-band Radarsat-1. This is a result of the interaction between the different wavelength of each satellite and the vegetation [11]. Radarsat- 1 produces less coherent results because its shorter wavelength (C-band $5.6 \mathrm{~cm}$ ) interacts with leaves and soft stem vegetation, which change rapidly with time. The L-band ALOS $(24 \mathrm{~cm})$ signal penetrates through tree canopies and interacts with branches and tree trunks, which have fewer changes over time.

Coastal wetlands phase changes are characterized by short wavelength patterns and require zooming into some specific areas (Figures 4 and 5). Interferograms from the western most part of coastal Louisiana, the Chenier Plane, show a group of fringe discontinuities aligned with the coastline and relate to the coastal geomorphology in that area (Figure $4 \mathrm{a}, \mathrm{d}$ ). The Chenier Plane is a zone of ridges aligned parallel to the coast; the ridges are 20 to $30 \mathrm{~km}$ long and 2 to $6 \mathrm{~m}$ high with large mudflats covered with wetland vegetation [30]. InSAR results also show that due to disruptions of the tidal flow along the west Chenier Plain, the extent of tidal inundation ranges between $800 \mathrm{~m}$ to $2 \mathrm{~km}$. In the center and east of the Chenier Plain, both ALOS and Radarsat interferograms show noticeable phase discontinuities on different locations along the coastline. The mapped tidal zone in this area extends between 2-4 km (Figures 4a,b and 5d). For the Mississippi River delta, ALOS results show fringe changes due to both natural tidal inundation and anthropogenic activity (Figure 5). Fringe changes due to tidal inundation are most apparent west of the Mississippi delta, where the interferogram shows two fringe cycles, $5 \mathrm{~km}$ to the west side and $15 \mathrm{~km}$ to the east side, of tidal inundation change over the coast (Figure 5g). The observed discontinuities for this area coincide with man-made structures that where present along the Mississippi River delta (Figure 5a,b). Our results indicate that from the total $743 \mathrm{~km}$ length of the Louisiana coast, tidal inundation shows to be disrupted by man-made canals in roughly $45 \%$ of the coast and levees disruptions are observed in $15 \%$ of the coast length.

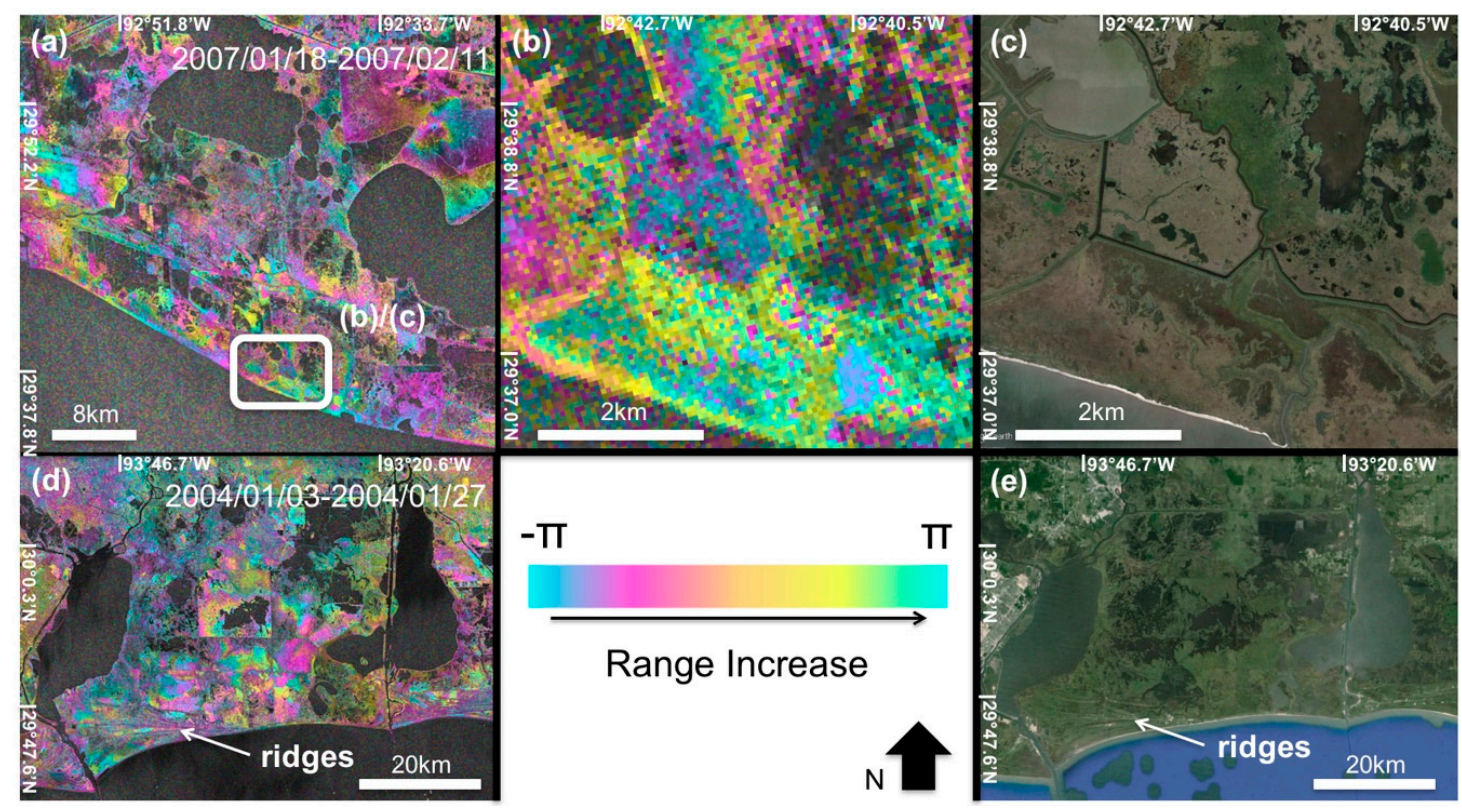

Figure 4. (a) Radarsat-1 interferograms of the central part of the Chenier Plain spanning 24 days (18 January 2007-11 February 2007). The white square shows the location of figures (b,c); (b) Zoom in showing fringe discontinuities sub-parallel to the coastline that coincides with man-made canals observed in the Google Earth image (c); (c) Google earth image of the same area; (d) Radarsat-1 interferogram of the western Chenier Plain spanning 24-day period (3 January 2004-27 January 2004). In the central part of the interferogram fringe patterns show changes in inland water bodies. The white square on the left side of the interferogram shows fringe patterns due to the morphology of the Chenier reflecting water level changes in the mudflats in between the ridges of the Chenier's; (e) Google earth image of the same study area. 


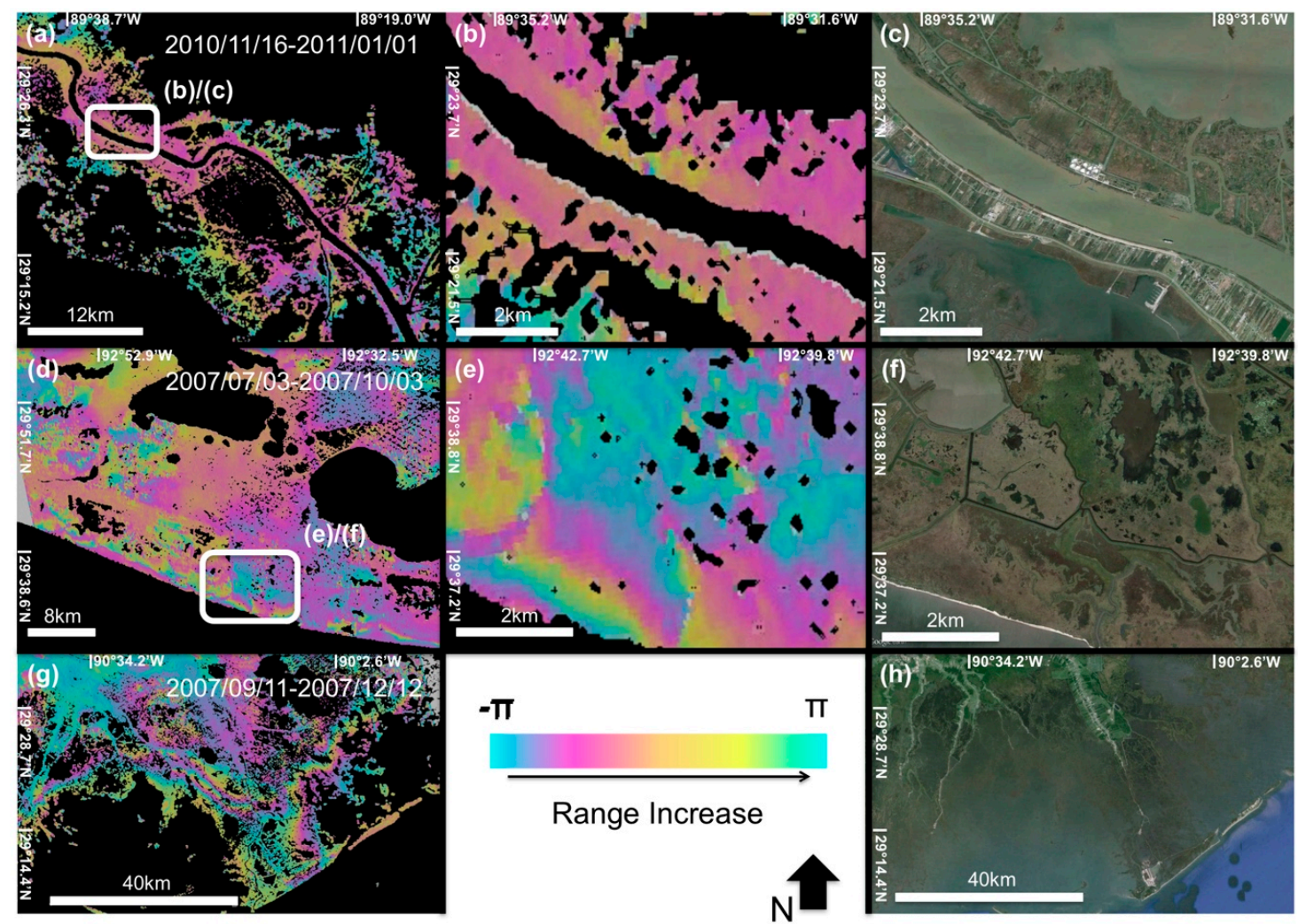

Figure 5. (a) ALOS interferograms of the Mississippi Delta showing phase change due to water level changes, spanning 46 days between acquisitions (16 November 2010-1 January 2011); (b) Zoom in area showing phase change due to tide inundation disruption caused by the presence of levees along the river; (c) Google earth image of the same study area; (d) ALOS interferogram of the central Chenier Plain showing phase changes due to water level changes, spanning 92 days (3 July 2007-3 October 2007); (e) Elongated fringe patterns sub-parallel to the coastline coinciding with man-made canals; (f) Google Earth image of the same study area; (g) ALOS interferogram of the west of the Mississippi River delta, spanning 92-day period (11 September 2007-12 December 2007). The interferogram shows fringe patterns due to tidal induced water level changes; (h) Google earth image of the same study area.

\section{Discussion}

The use of L-band and C-band sensors allowed us to detect different type of tide inundation disruptions along coastal Louisiana due to the difference in wavelength and repeat pass time. We focus our analysis on short wavelength changes, because the interaction between the tide inundation and land or man-made structures happens in localized areas over a few kilometer distance. The Chenier Plane is characterized by phase changes caused by three main causes, which are ridge morphology, inland water bodies, and man-made structures (Figure 4). For this area we found that both ALOS (L-band) and Radarsat-1 (C-band) results show phase disruptions that correlate with numerous man-made canals, dredged mainly for oil recovery or navigation purposes (Figures $4 \mathrm{~b}$ and 5e). However, Radarsat-1 results also show very short wavelength fringe patterns parallel to the coast due to the geomorphology of the Cheniers (Figure 4d). The geomorphology of the Chenier has been affected by anthropogenic activities including sand mining, road constructions and colonization as described in the Cheniers and Natural Ridges Study of the State of Louisiana (2009). The short wavelength of Radarsat-1 $(5.66 \mathrm{~cm})$ enables the satellite to detect phase changes, where ALOS failed to detect. The subtle phase changes induced by the Chenier geomorphology are too small for the $24 \mathrm{~cm}$ wavelength of L-band to be detected. Two main types of phase changes, tide inundation disruptions and water level changes through the tidal flush zone characterize the area of the Mississippi River delta. ALOS interferograms were able to detect short wavelength tidal flow disruptions, similar to the ones 
in Radarsat-1 results, mainly due to levee construction for flood protection (Figure 5a). Interferograms of the western side of the Mississippi River delta show a group of elongated fringes that map the tidal flush zone in that region (Figures 5g, 6 and 7a). Sea level changes in the tidal flush zone are detected because it is an emerged vegetation environment with changing water levels. Although tide-induced water level changes occur also further south in the open water, the lack of vegetation prevents a coherent interferometric signal in such environment (Figure 6). Further north the tidal flush zone is delimited by a man-made canal that interrupts the tidal inundation, obstructing the path to its natural limit in higher lands.

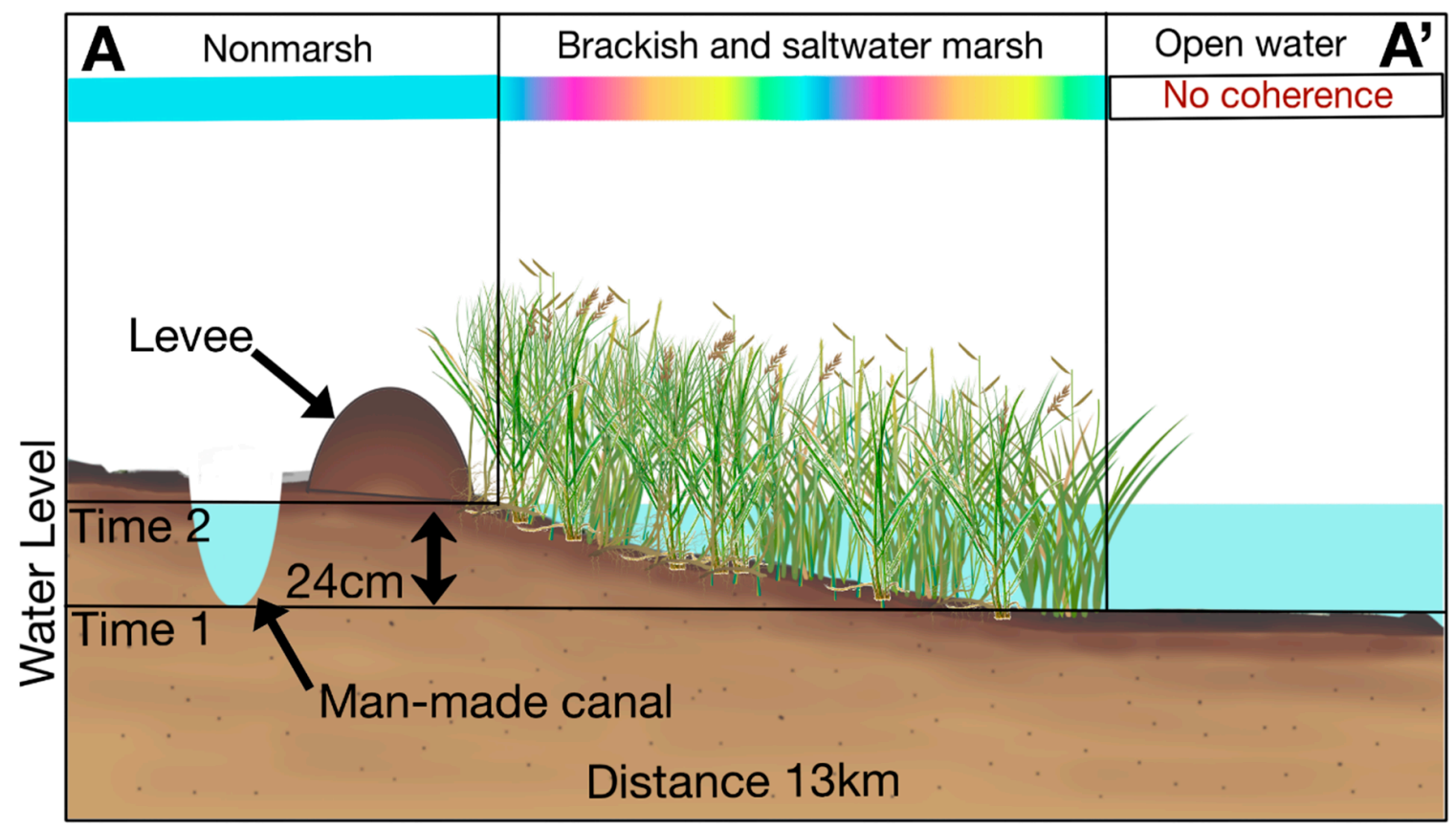

Figure 6. Schematic diagram showing the topography, vegetation and tidal induced level change along transect A-A'.

The highest fringe gradient was found along the coastal wetlands in Timbalier bay, Caminada bay and Barataria bay, west of the Mississippi River delta (Figures 5g,h and 7a). However, not all interferograms of the same area show the same amount of fringe changes. For example, the 46-day interferogram of 16 March 2009-1 May 2009 shows no phase change between the acquisitions (Figure 7b). In contrast the 11 September 2007-12 December 2007 interferogram (Figure 7a) shows a set of two fringe cycles, which represent a change of $30 \mathrm{~cm}$ of vertical motion occurring between the open water of the Gulf and the wetlands further inland. In order to understand this inconsistent fringe pattern, we compared the InSAR results with the tide gauge information located closest to the area of interest. Due to the tide gauge station distribution and the few places where natural tidal inundation can be observed, the comparison between tide gauges and InSAR results was conducted only for the results of ALOS track 166 and data acquired by the Port Fourchon station (Figure 7a,b). We use a 24-h period of tide information from each acquisition, using Greenwich Mean Time (GMT) and 6 min sampling. We mark the acquisition time of the satellite on the plots (red vertical line in Figure 7d,e) and calculate the water level elevation difference between the two acquisition times, which we compare with the InSAR derived water level change. We also use the NOAA's predicted data for the station, to verify that no extreme events occurred during the InSAR acquisition time that may have affected the InSAR results. The tide gauge records show a water level change of $24 \mathrm{~cm}$ between 11 September 2007-12 December 2007 and 5 cm between 16 March 2009 and 1 May 2009, which are consistent with differences in the fringe pattern of the interferograms in Figure 7. 


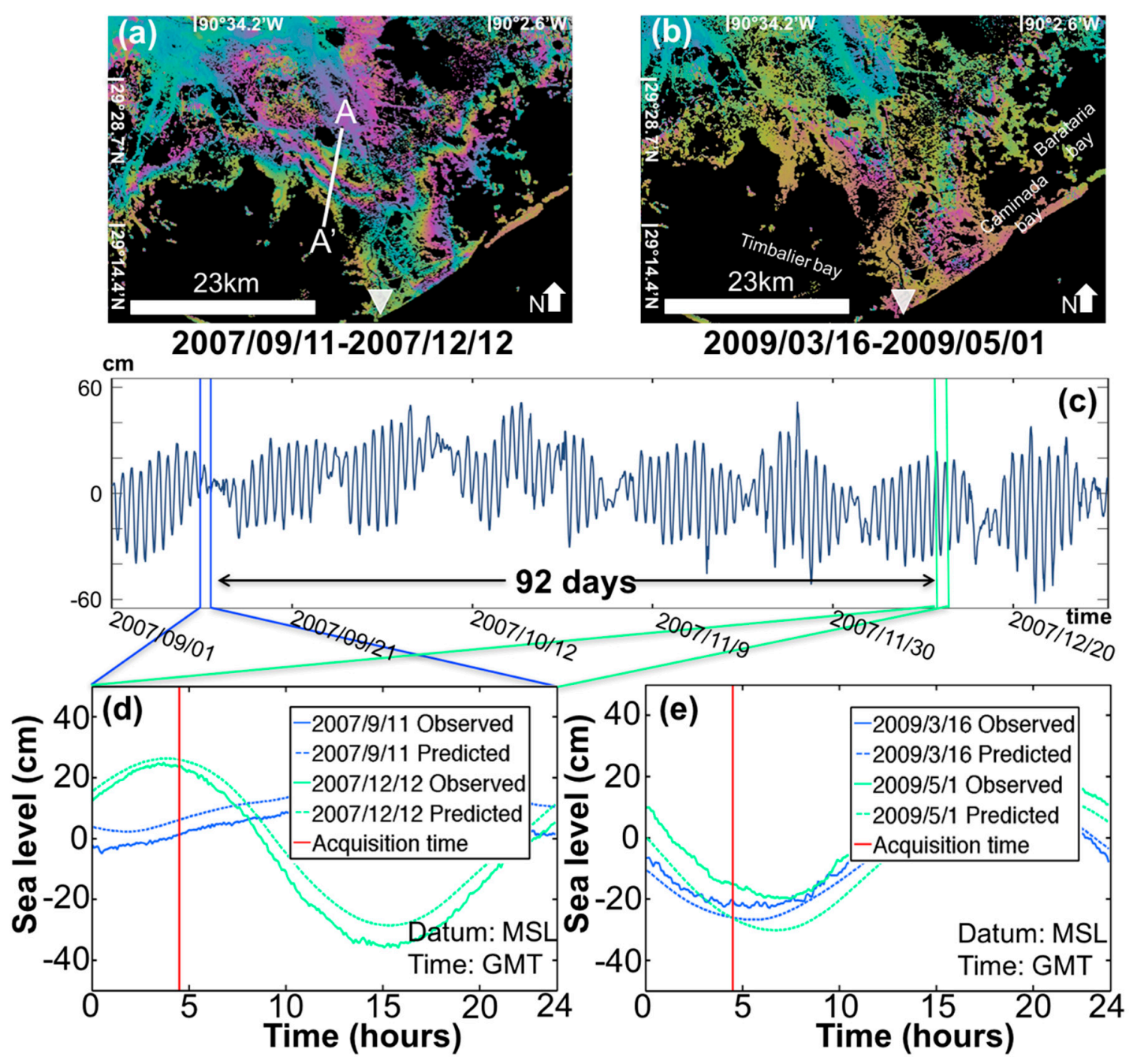

Figure 7. (a) ALOS interferogram of track 166 showing two fringe cycles across the tidal zone mapping the tide inundation extent. The white triangle marks the location of the Port Fourchon gauge station. The white line shows the location of the section described on Figure 7; (b) ALOS 16 March 2009-1 May 2009 interferogram of the same track showing no fringes; (c) Port Fourchon tide gauge data from 1 September 2007 to 31 December 2007. The blue and green vertical lines show the 24-h period recorded by the tide gauge for the two acquisition dates of interferogram (a); (d) Port Fourchon tide gauge predicted (solid) and observed (dashed) records plotted for 24-hour periods of the two acquisition dates (11 September 2007 in blue and 12 December 2007 in green). The red vertical line marks the ALOS acquisition time 4:32 GMT, which shows roughly $25 \mathrm{~cm}$ water level differences between the two acquisitions; (e) A similar tide gauge analysis for the two acquisition dates of the interferogram (b) showing only $5 \mathrm{~cm}$ of water level change between the two acquisition times.

The time difference between the ALOS satellite repeat orbit (46 days) and tidal cycle enables InSAR detection of tide-induced water level variations (Figure 7d). However, if the satellite acquisitions and the tidal changes were synchronized, InSAR observations will not be able to detect tide-induced water level changes occurring at the same tidal amplitude. The tide has both a near daily $(23 \mathrm{~h})$ and a two-week cycle, whereas the satellites are sun-synchronous and acquire data exactly at the same time of the day. The phase shift between satellite acquisitions and tide condition results in satellite observations that are collected at different amplitude positions of the tide cycle. The 46-day interferograms have a small amplitude shift (3 days) producing a minor difference between acquisitions and, thus, showing no noticeable tide induced changes in the interferogram. The 92-days interferogram observations are located almost in opposite sides of the tide amplitude cycle, allowing InSAR to better detect differences 
in the tide inundation level. With the 3-5 cm accuracy of L-band observations $[8,10]$, the patterns inferred from the fringes, which are in the range of $7-30 \mathrm{~cm}$, bearing the method uncertainty level and hence conclusions made are solid.

The mapped tidal inundation extents provide a good perspective of tidal inundation through Louisiana coastal wetlands (Figure 8). The detected tidal inundation extent in the central part of the coast shows an area of approximately $65 \mathrm{~km}$ long and $15 \mathrm{~km}$ wide area of fresh marsh that is being flushed by tidal currents (Figures 8 and 9c). Detailed observations of the tidal inundation extent along the coast of Louisiana confirmed that the majority of the tidal inundation is being disrupted by man-made canals and other structures along most of the coast (Figure 9).

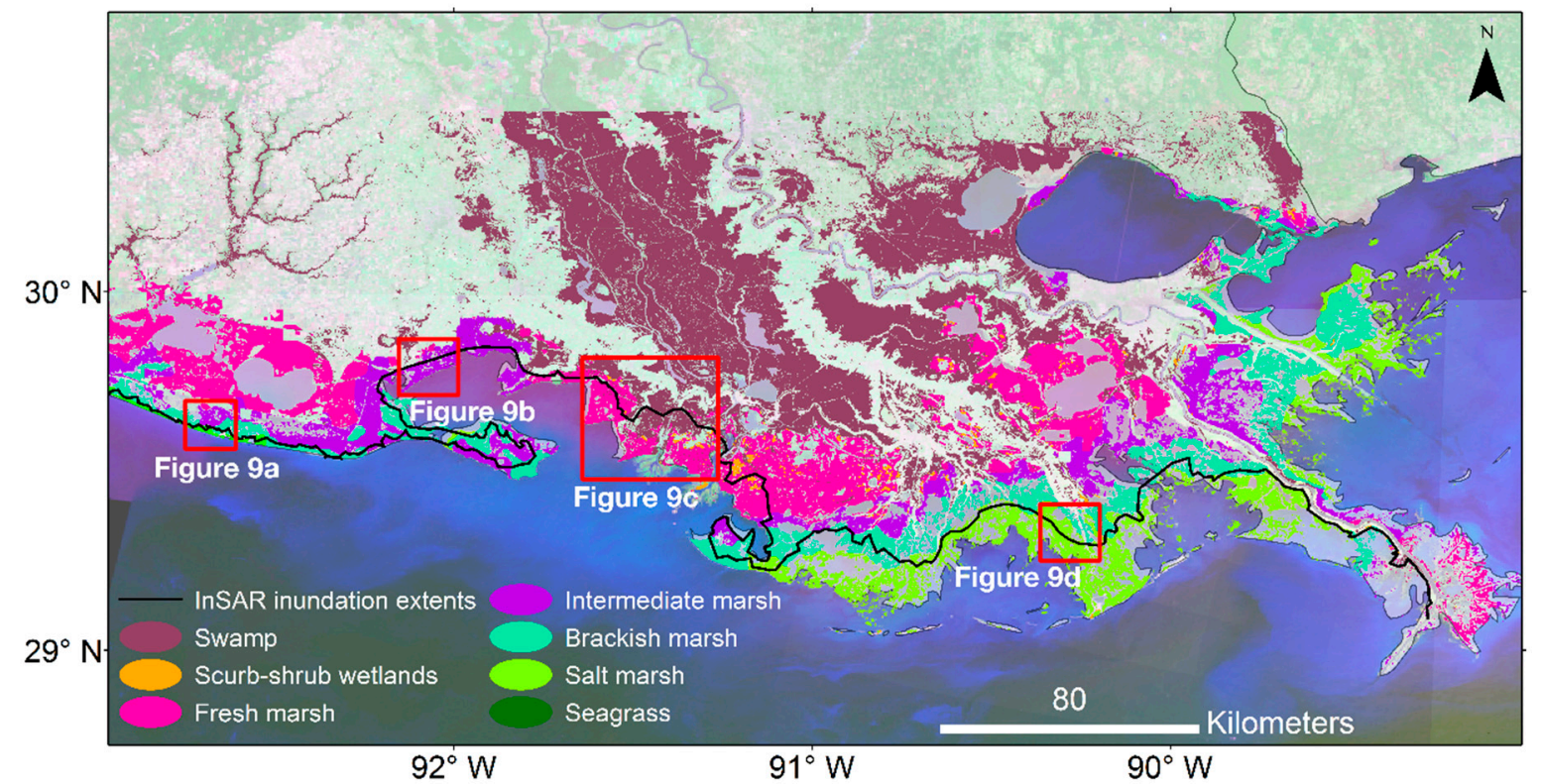

Figure 8. Wetland classification map from Gulf-Wide Information System (G-WIS) [19] and InSAR detected tidal inundation extents through Louisiana coastal wetlands (black line). The red frames show the location of detailed observations presented in Figure 9.

The tidal zone along coastal Louisiana shows to be delimited mainly by dredged canals and levees, leaving narrow areas of uninterrupted tidal inundation. Some areas show disruptions by both levees and man-made canals (Figure 9c) while others are disrupted by canals before reaching the populated areas where most of the levees are located (Figure 9d). Our results show that at present approximately $40 \%$ of the Louisiana coast is subjected to uninterrupted tidal inundation. However, with rising sea levels and continuous coastal subsidence the length of the shoreline with uninterrupted tidal inundation will decrease due to the existence of man-made structures at short distances $(1-6 \mathrm{~km})$ inland of the current tidal inundation zone.

Disruptions along the Louisiana coast are major factors of wetland loss. Anthropogenic intervention is transforming coastal Louisiana, changing the natural tide interaction with the coast and changing the regular sediment deposition with it. The dredged canals that interrupt the water flow work as barriers that divide and separate the coastal wetlands. The dissected wetlands become more sensitive to sea level rise of $3.2 \pm 0.4 \mathrm{~mm} /$ year [31] and ultimately dying due to land subsidence and increasing sea level.

This study mainly focuses on the analysis of the interaction between tidal inundation and the coastal wetlands of Louisiana by observing changes in the water level along the coast. However it is important to mention that coastal wetlands are strongly affected and driven by temperature changes, rainfall regimes and sea-level rise [32], and they play a permanent role in the synergy between the coastal wetlands and the tidal flow. Nevertheless, our study shows that man-made structures along 
the Louisiana coast have changed the regular patterns of tidal inundation through coastal wetlands and, hence, have become a dominant element in determining coastal wetland distribution.
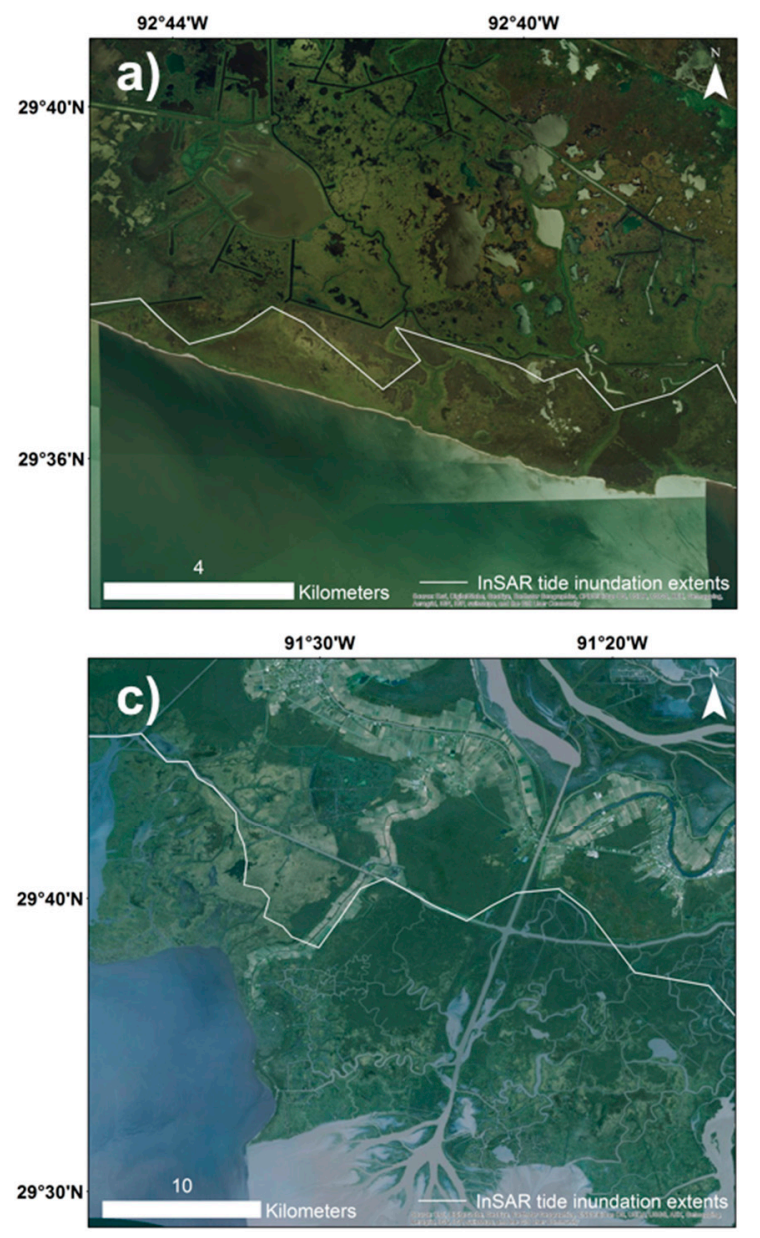
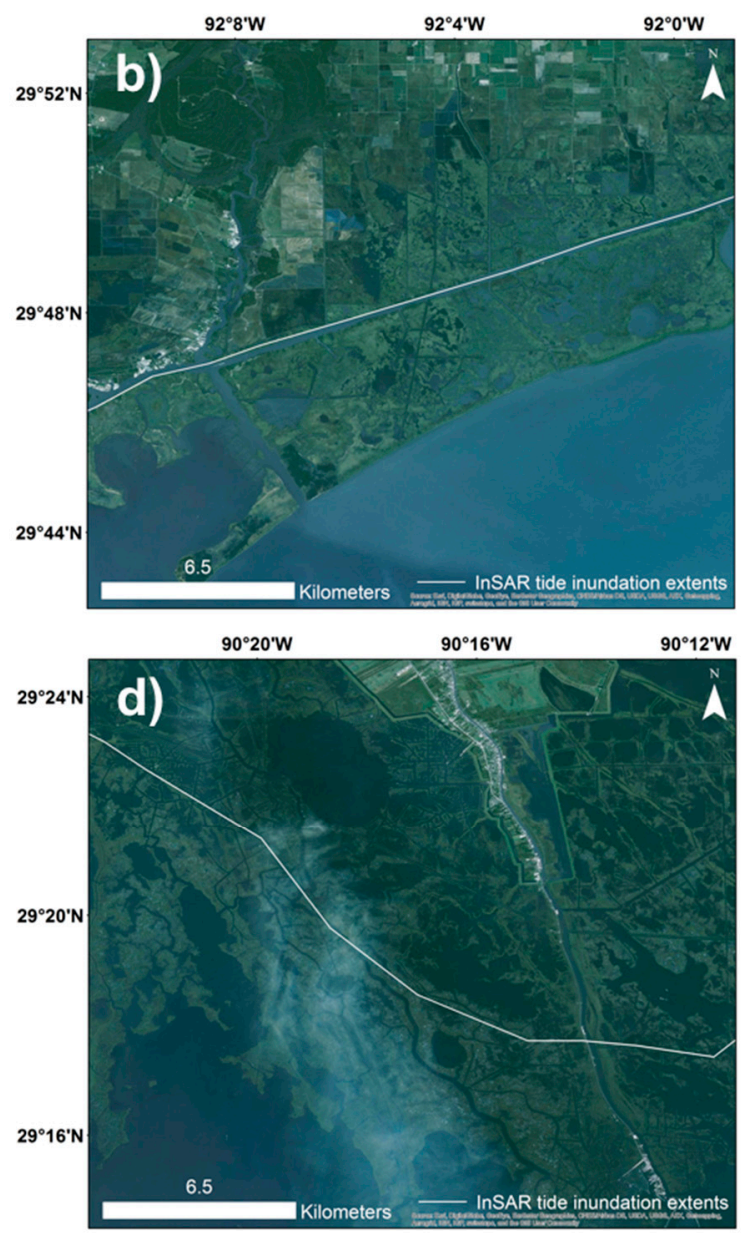

Figure 9. Zoom-in maps showing geographical features along the InSAR detected boundary of tidal inundation extents: $(\mathbf{a}, \mathbf{b})$ Chenier Plane; (c) central coast of Louisiana and (d) Timbalier bay, west of the Mississippi River delta. Satellite images source: Esri ArcGIS ${ }^{\circledR}$ world imagery basemap.

\section{Conclusions}

The analysis of four Radarsat- 1 and twelve ALOS swaths over the Louisiana coast reveals that tidal inundation is restricted to narrow areas along the coast, where the tide can flow regularly. InSAR results show that the Chenier Plain has the narrowest tidal zone, reaching a maximum of $2 \mathrm{~km}$ in some parts, and the Mississippi River delta has wider zones reaching up to $15 \mathrm{~km}$. InSAR technique showed to be an effective tool to map and measure the extents and amplitude of the tide inundation zone through Louisiana coastal wetlands, as well as to detect areas of tidal flow disruptions along the coast. Detailed observations of the produced interferograms indicate that man-made canals and levees are the main sources of tide disruptions along the entire coast.

A comparison between InSAR detected water level changes and tide gauge records indicate that interferometric observations in coastal wetlands highly depend on the tide-induced water level changes observed between satellite acquisitions. In the case of the coast of Louisiana, the 92-day ALOS interferograms observe larger tide-induced water level changes than the 46-day ones, providing clearer information of the tidal inundation extents. Although our study is limited to the Louisiana coast, the use of this technique can be expanded to detect tidal inundation interactions in similar coastal zones. The implementation of InSAR as a monitoring tool to detect tidal inundation propagation can provide 
useful constrains for coastal tidal inundation models, and can be used to detect and track sources of tidal flow disruptions.

Supplementary Materials: The following are available online at www.mdpi.com/2072-4292/8/5/393/s1, Table S1: Satellite specifications. Figure S1: ALOS 46-92 day interferograms from track 166.

Acknowledgments: Authors thank the three anonymous reviewers for their very helpful comments on the manuscript. We would like to thank Sang-Hoon Hong and Heresh Fattahi for their help processing the InSAR data. We also acknowledge help of the Japan Aerospace Exploration Agency (JAXA), the Canadian Space Agency (CSA), the Alaska Satellite Facility (ASF) and the National Oceanic and Atmospheric Administration (NOAA) for providing access to the satellite images and tide gauge station information. We thank the Fulbright and CONACYT grants for their support of the first author. The research was supported by the National Science Foundation through Research program under Grant No. DEB-1237517.

Author Contributions: Talib Oliver was responsible for InSAR and tide-gauge data processing. Both authors contributed to the data interpretation and the writing of the manuscript.

Conflicts of Interest: The authors declare no conflict of interest.

\section{References}

1. Gallant, A.L. The challenges of remote monitoring of wetlands. Remote Sens. 2015, 7, 10938-10950. [CrossRef]

2. Couvillion, B.R. Land Area Change in Coastal Louisiana (1932 to 2010); US Department of the Interior, US Geological Survey: Reston, VA, USA, 2011.

3. Penland, S. Geomorphic classification of coastal land loss between 1932 and 1990 in the Mississippi River Delta Plain, Southeastern Louisiana. USGS Open-File Report 00-417; US Geological Survey Woods Hole: Barnstable County, MA, USA, 2000.

4. Steyer, G.D.; Couvillion, B.R.; Barras, J.A. Monitoring vegetation response to episodic disturbance events by using multitemporal vegetation indices. J. Coast. Res. 2013, 63, 118-130. [CrossRef]

5. Barras, J. Historical and Projected Coastal Louisiana Land Changes: 1978-2050; United States Geological Survey: Reston, VA, USA, 2003.

6. Ramsey, E.; Rangoonwala, A.; Bannister, T. Coastal flood inundation monitoring with satellite C-band and L-band synthetic aperture radar data. JAWRA J. Am. Water Resour. Assoc. 2013, 49, 1239-1260. [CrossRef]

7. Moffett, K.B. Multiple stable states and catastrophic shifts in coastal wetlands: Progress, challenges, and opportunities in validating theory using remote sensing and other methods. Remote Sens. 2015, 7, 10184-10226. [CrossRef]

8. Wdowinski, S. Space-based detection of wetlands' surface water level changes from L-band SAR interferometry. Remote. Sens. Environ. 2008, 112, 681-696. [CrossRef]

9. Kim, J.-W. Integrated analysis of PALSAR/Radarsat-1 InSAR and ENVISAT altimeter data for mapping of absolute water level changes in Louisiana wetlands. Remote Sens. Environ. 2009, 113, 2356-2365. [CrossRef]

10. Sang-Hoon, H.; Wdowinski, S.; Sang-Wan, K. Evaluation of TerraSAR-X Observations for Wetland InSAR Application. IEEE Trans. Geosci. Remote Sens. 2010, 48, 864-873. [CrossRef]

11. Kim, S.-W. Interferometric Coherence Analysis of the Everglades Wetlands, South Florida. IEEE Trans. Geosci. Remote Sens. 2013, 51, 5210-5224. [CrossRef]

12. Pritchard, M.E. InSAR, a tool for measuring Earth's surface deformation. Phys. Today 2006, 59, 68. [CrossRef]

13. Lu, Z.; Kwoun, O.-I. Radarsat-1 and ERS InSAR analysis over southeastern coastal Louisiana: Implications for mapping water-level changes beneath swamp forests. IEEE Trans. Geosci. Remote Sens. 2008, 46, 2167-2184. [CrossRef]

14. Elijah, R., III; Lu, Z.; Rangoonwala, A.; Rykhus, R. Multiple baseline radar interferometry applied to coastal land cover classification and change analyses. GISci. Remote Sens. 2006, 43, 283-309.

15. Wdowinski, S. Remote-sensing monitoring of tide propagation through coastal wetlands. Oceanography 2013, 26, 64. [CrossRef]

16. Boesch, D.F.; Josselyn, M.N.; Mehta, A.J.; Morris, J.T.; Nuttle, W.K.; Simenstad, C.A.; Swift, D.J. Scientific assessment of coastal wetland loss, restoration and management in Louisiana. J. Coast. Res. 1994, 20, i-103.

17. Owen, D.E. Geology of the Chenier Plain of Cameron Parish, southwestern Louisiana. Field Guides 2008, 14, $27-38$. 
18. Sasser, C.E. Vegetation types in coastal Louisiana in 2013. U.S. Geological Survey Scientific Investigations Map 3290; US Department of the Interior, US Geological Survey: Reston, VA, USA, 2013.

19. Minerals Management Service. G-WIS Environmental Sensitivity Index Datasets; Minerals Management Service: New Orleans, LA, USA, 2002.

20. MDA Federal. Landsat Geocover 2000/ETM+ Edition Mosaics. Available online: http://glcf.umd.edu/ data/mosaic/ (accesed on 5 July 2015).

21. Bernier, J. Trends and Causes of Historical Wetland Loss in Coastal Louisiana. Available online: http:/ / pubs.usgs.gov/fs/2013/3017/ (accessed on 4 May 2016).

22. Dixon, T.H. Space geodesy: Subsidence and flooding in New Orleans. Nature 2006, 441, 587-588. [CrossRef] [PubMed]

23. Morris, J.T. Responses of coastal wetlands to rising sea level. Ecology 2002, 83, 2869-2877. [CrossRef]

24. University of Alaska Fairbanks. The National Aeronautics and Space Administration. Available online: https:/ / ursa.asfdaac.alaska.edu/ (accessed on 5 February 2015).

25. Richards, J.; Woodgate, P.; Skidmore, A. An explanation of enhanced radar backscattering from flooded forests. Int. J. Remote Sens. 1987, 8, 1093-1100. [CrossRef]

26. Wdowinski, S.; Hong, S.-H. 7 Wetland InSAR. In Remote Sensing of Wetlands: Applications and Advances; CRC Press: Boca Raton, FL, USA, 2015.

27. Rosen, P.; Fielding, E. Repeat Orbit Interferometry Package (ROI_PAC). Available online: http://roipac.org/ (accessed on 6 May 2016).

28. Hanssen, R.F. Radar Interferometry: Data Interpretation and Error Analysis; Springer Science \& Business Media: Berlin, Germany, 2001.

29. The National Oceanic and Atmospheric Administration. Center for Operational Oceanographic Products and Services. Available online: http:/ / tidesandcurrents.noaa.gov/ (accessed on 5 May 2016).

30. Penland, S.; Suter, J.R. The geomorphology of the Mississippi River Chenier plain. Mar. Geol. 1989, 90, 231-258. [CrossRef]

31. Church, J.A.; White, N.J. Sea-level rise from the late 19th to the early 21st century. Surv. Geophys. 2011, 32, 585-602. [CrossRef]

32. Osland, M.J. Beyond just sea-level rise: Considering macroclimatic drivers within coastal wetland vulnerability assessments to climate change. Glob. Chang. Biol. 2016, 22, 1-11. [CrossRef] [PubMed]

(C) 2016 by the authors; licensee MDPI, Basel, Switzerland. This article is an open access article distributed under the terms and conditions of the Creative Commons Attribution (CC-BY) license (http://creativecommons.org/licenses/by/4.0/). 